\title{
Clinical and epidemiological features of an outbreak of acinetobacter infection in an intensive therapy unit
}

\author{
M. CROWE, K. J. TOWNER and H. HUMPHREYS
}

Department of Microbiology and PHLS Laboratory, University Hospital, Queen's Medical Centre, Nottingham NG7 $2 \mathrm{UH}$

\begin{abstract}
Summary. Sporadic examples of infection with multi-resistant Acinetobacter spp. have occurred in Nottingham hospitals since at least 1977, punctuated by more prolonged outbreaks involving larger numbers of patients, particularly those confined to the intensive therapy unit (ITU) with severe underlying disease. In the most recent outbreak, 11 patients were infected with multi-resistant Acinetobacter strains and 26 patients were colonised. Four of the infected patients died directly or indirectly from infection with multi-resistant Acinetobacter spp., either while in the ITU or after discharge to a general ward. The mean interval from admission to the first isolation of a multi-resistant Acinetobacter strain was 6.7 and 12.1 days in the infected and colonised groups, respectively. Multi-resistant Acinetobacter strains were isolated most frequently from the respiratory tract, and eight patients had probable or suspected pneumonia caused by a multi-resistant Acinetobacter sp. All infected patients were treated with imipenem, with or without an aminoglycoside, except one patient who died before a diagnosis of acinetobacter infection was confirmed. Multi-resistant Acinetobacter spp. were isolated from various environmental sites in the ITU, and patient and environmental isolates were found to be related closely by biotyping, antibiograms, pulsedfield gel electrophoresis of chromosomal fingerprints and ribotyping. The outbreak was controlled ultimately by transfer of infected or colonised patients to an isolation cubicle, cohort nursing, emphasis on the importance of hand washing before and after patient contact and when handling case notes, and the use of disposable aprons and gowns during patient contact. These measures were combined with closure of the ITU for decontamination purposes on two separate occasions. Continued surveillance of ITU patients and occasional environmental sampling has proved to be important in preventing and controlling subsequent outbreaks of infection by this increasingly important nosocomial pathogen.
\end{abstract}

\section{Introduction}

Members of the genus Acinetobacter are small, nonfermentative gram-negative bacilli that are found commonly in soil, water and as part of the normal flora on human skin and in the gastrointestinal and upper respiratory tracts. The genus comprises at least 19 different DNA groups (genospecies), ${ }^{1}$ some of which are distributed widely in most hospital environments and have long been recognised as occasional opportunist pathogens causing bacteraemia, pneumonia, wound and urinary tract infection. ${ }^{2,3}$ However, a dramatic increase in the incidence of infections caused by these organisms has been noted over the past decade, particularly when compared with other common organisms causing nosocomial infec- tion. In some centres it has been reported that an Acinetobacter sp. is now the most common pathogen associated with nosocomial infection, and may comprise between 1 and $9 \%$ of all bacterial species isolated from clinical specimens. ${ }^{4}$ This applies particularly to intensive therapy units (ITUs), where risk factors for colonisation and infection include mechanical ventilation, hyperalimentation, peripheral or arterial catheterisation, and antibiotic therapy. ${ }^{5-7}$ The marked increase in the incidence of acinetobacter infections has been associated with high rates of resistance to most available antibiotics (sometimes including imipenem and the new fluoroquinolones) in Acinetobacter spp., with the result that many established infections are extremely difficult to treat. ${ }^{8}$

In Nottingham hospitals, sporadic examples of infection with multi-resistant Acinetobacter spp. have occurred since at least 1977. These have been 
punctuated by more prolonged outbreaks involving larger numbers of patients, particularly those confined to the ITU with severe underlying disease. Transmission is thought to occur through contact with contaminated apparatus such as nebulisers, contact with the colonised skin of patients or staff, or by the airborne route. ${ }^{3.9}$ Investigations to trace the source and routes of transmission of epidemic strains, as a first step in devising strategies to prevent or control outbreaks, have been hampered in the past by the absence of reliable or widely available typing techniques. Various conventional typing systems have been investigated (including serotyping, phage typing, bacteriocin typing. plasmid analysis and biotyping), but it has been concluded that a single reliable conventional typing system for Acinetobacter spp. does not exist at present. ${ }^{10}$ Alternatives in the form of molecular typing methods for nucleic acids and proteins are now becoming available, ${ }^{11-15}$ and these show considerable promise as epidemiological tools. The present paper describes the clinical and epidemiological features of the most recent outbreak of infection with multi-resistant Acinetobacter spp. at University Hospital, Nottingham, which occurred in the adult ITU during 1992-93.

\section{Patients and methods}

\section{Patients and sampling}

The adult ITU. The University Hospital ITU contains nine beds, including one isolation cubicle, and c. 650 patients are admitted each year. The main reasons for admission are resuscitation and organ support after multiple trauma, post-operative care, and requirement for ventilation because of respiratory failure or pneumonia. The severity of the patient's illness and underlying disease are scored on admission with the Acute Physiology and Chronic Health Evaluation (APACHE II) ${ }^{16}$ The unit is visited each day by a medical microbiologist who advises on the diagnosis and management of infection. Specimens are taken from patients as indicated clinically, or when requested by a medical microbiologist.

Infection, colonisation and specimens. Unit-acquired infection caused by Acinetobacter spp. was defined as that occurring $48 \mathrm{~h}$ or more after admission, with a diagnosis of bacteraemia, wound, urinary or intravascular infection made according to standard criteria. $^{17.18}$ Suspected or probable pneumonia was diagnosed on clinical criteria (i.e., presence of fever, infiltrates on chest X-ray etc.) accompanied by the isolation of Acinetobacter spp. from endotracheal aspirates or sputum. Colonisation with Acinetobacter spp. was defined as the isolation of the organism from one or more superficial sites on one or more occasions in the absence of symptoms or signs of systemic infection (e.g., fever) requiring antimicrobial therapy. Urine, sputa, wound swabs, intravascular tips etc., were processed by standard methods. ${ }^{19}$ Aerobic and anaerobic blood cultures were processed conventionally. with a Gram's stain and subculture into a Casteneda biphasic medium ${ }^{20}$ being done on arrival of the bottles in the laboratory. Subsequently, blood culture bottles were inspected daily and subcultured on to solid media if cloudy and routinely after 7 days. Where the patient's condition allowed, pneumonia was confirmed by culture of broncho-alveolar lavage (BAL) obtained by bronchoscopy, with a bacterial count of $\geqslant 10^{4} \mathrm{cfu} / \mathrm{ml}$ deemed to be significant. ${ }^{21}$

Enironmental investigations. The immediate environment of infected or colonised patients, and the general environment of the ITU, was screened for the presence of multi-resistant Acinetobacter spp. on three occasions during the outbreak (on 12 Dec. 1992, 4 Feb. 1993 and 10 Feb. 1993) and once after the end of the outbreak (on 27 April 1993). Sites screened, including horizontal surfaces, cot sides, trunking carrying electrical and oxygen supplies above the patient, mattresses, etc., were chosen on the basis of previously reported sites of possible environmental contamination with Acinetobacter spp., ${ }^{2,3}$ and were sampled with swabs moistened in saline $0.9 \%$. These were inoculated on to CLED Agar (Oxoid CM301) plates containing gentamicin $10 \mathrm{mg} / \mathrm{L}$ (chosen on the basis of sensitivity patterns observed during the previous 15 years). Air sampling was performed with a Surface Air System sampler (Cherwell Laboratories, Bicester) in the vicinity of positive (i.e., infected or colonised) patients and elsewhere within the unit. Four to six air samples, each of $900 \mathrm{~L}$, were taken on each occasion with $55 \mathrm{~mm}$ diameter contact plates. Colony counts were expressed as $\mathrm{cfu} / \mathrm{m}^{3}$, corrected with standard statistical methods. ${ }^{22}$

\section{Identification and typing methods}

Identification. Acinetobacter spp. were identified on the basis of colonial morphology (lactose-negative convex colonies on MacConkey or CLED agar), microscopic appearance in Gram's stain, a negative oxidase reaction, and a series of in-house biochemical and other tests, such as motility, utilisation of various sugars, etc., derived from standard methods. ${ }^{23}$

Biotyping and antibiograms. All isolates were biotyped with the API 20NE system (bioMérieux). Antibiograms were determined by inoculating $1-\mu 1$ spots of an overnight Nutrient Broth (NB; Oxoid CM67) culture on to IsoSensitest Agar (Oxoid CM71) plates containing doubling dilutions of individual antibiotics obtained from standard commercial sources. MICs were recorded as the lowest concentration of an antibiotic that prevented visible bacterial growth after incubation of the plates at $30^{\circ} \mathrm{C}$ overnight.

Pulsed-field gel electrophoresis (PFGE) fingerprints. Intact chromosomal DNA was prepared in agarose plugs by the method of Curran et al. ${ }^{24}$ from cultures of Acinetobacter strains grown overnight in NB on an 
orbital shaker $(200 \mathrm{rpm})$ at $30^{\circ} \mathrm{C}$. Digestion of DNA in agarose plugs with Apal (Northumbria Biologicals) and subsequent PFGE were also as described previously. ${ }^{24}$ After electrophoresis, gels were stained for $45 \mathrm{~min}$ with ethidium bromide $0.5 \mathrm{mg} / \mathrm{L}$ in electrophoresis buffer. ${ }^{24}$ and were then destained briefly with distilled water. DNA fingerprints were visualised on a TM-36 UV Transilluminator (Ultra-Violet Products Inc., San Gabriel. CA. USA) and photographed through a red filter with Polaroid Type 667 Film.

Ribotyping. DNA fingerprints were first transferred from agarose gels to nylon membranes (Hybond-N; Amersham) with a Capillary Blotting Unit (Scotlab. Coatbridge, Strathclyde) and were then cross-linked to the membranes by exposure to UV light as described previously." For ribotyping, the membranes were probed with a 5'-digoxigenin-labelled oligonucleotide (5'-GCTGCCTCCCGTAGGAGT-3'; custom synthesised by R and D Systems Europe, Abingdon) specific for repetitive $16 \mathrm{~S}$ rRNA. ${ }^{25}$ Pre-hybridisation, hybridisation and detection of positive hybridisation results were by means of the conditions and protocols recommended for use with a DIG Nucleic Acid Detection Kit (Boehringer Mannheim). Ribotyping and PFGE fingerprint patterns were subjected to computerised analysis with the Dendron system (Solltech Inc., Oakdale, IA, USA).

\section{Results}

\section{Course of the outbreak}

Between Oct. 1992 and April 1993, 37 patients were either colonised or infected with multi-resistant Acinetobacter spp. The outbreak was characterised by the intermittent isolation of multi-resistant Acinetobacter spp. from one or more patients throughout this period. The overwhelming majority of the patients involved had received previously one or more courses of antibiotics, and 26 had received an extended spectrum cephalosporin. Four patients died either directly or indirectly from infection on the unit or subsequently, after discharge to a general ward. Table I compares colonised and infected patients. The most common reason for admission was multiple trauma (eight colonised, five infected patients), followed by head injury with or without neurosurgery (10 colonised, two infected patients). The mean interval from admission to the first isolation of a multi-resistant Acinetobacter strain was 12.1 and 6.7 days in the colonised and infected groups, respectively. The respiratory tract, i.e., sputum or tracheal isolates, was the site from which multi-resistant Acinetobacter spp. were isolated most frequently (16 colonised, nine infected patients).

Details of infections with multi-resistant Acinetobacter spp. and their subsequent therapy are given in table II. Bacteraemia was confirmed microbiologically in two patients, and there was clinical evidence of bacteraemia in one further patient, despite failure to isolate the bacterium from blood cultures. In one patient in the colonised group, a multi-resistant Acinetobacter sp. was isolated from blood, but bacteraemia was thought unlikely on clinical grounds. There was heavy colonisation of the skin of this patient, and it was considered that this represented a probable source of contamination. Eight patients had probable or suspected pneumonia. All infected patients were treated with imipenem, with or without an aminoglycoside, except patient 10 who died before a diagnosis of infection with a multi-resistant Acinetobacter sp. was confirmed.

Multi-resistant Acinetobacter spp. were recovered from environmental samples on two of the three sampling dates during the outbreak. Fourteen of 51 sites were positive when sampled on 4 Feb. 1993, and four of 20 sites on $10 \mathrm{Feb}$. 1993. The areas contaminated most heavily with multi-resistant Acinetobacter spp. were cot sides, bed wheels, intravascular drip stands and horizontal surfaces. Only one air sample, taken near a colonised patient on $12 \mathrm{Dec}$. 1992, was positive, but other samples taken on that occasion were negative. Screening of the unit for the

Table I. Comparison of colonised and infected patients

\section{Characteristics}

Number

Mean age in years (range)

Mean APACHE II on admission (range)

Reason for admission to ITU

Mean interval to first isolation of

Acinetobacter spp. (range)

Mean number of sites colonised/infected with

Acinetobacter spp. (range)

Sites positive for Acinetobacter spp.
Colonised patients

Infected patients

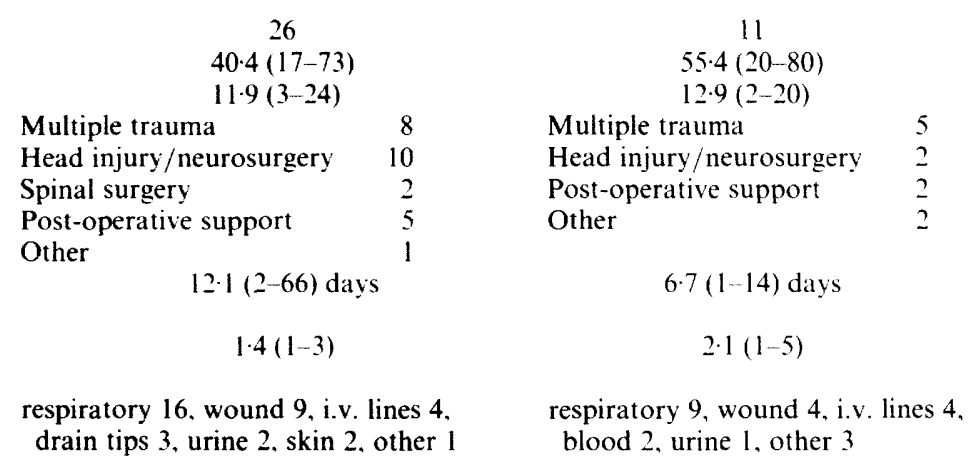

blood 2 , urine 1 , other 3 
Table II. Details of patients infected with Acinetobacter spp.

\begin{tabular}{|c|c|c|c|c|c|c|c|}
\hline $\begin{array}{l}\text { Patient } \\
\text { no. }\end{array}$ & $\begin{array}{l}\text { Age } / \text { sex } \\
\text { (y) }\end{array}$ & Underlying condition & $\begin{array}{l}\text { APACHE II } \\
\text { score }\end{array}$ & $\begin{array}{l}\text { Sites positive for } \\
\text { Acinetobacter spp. }\end{array}$ & Infection & Treatment & Outcome \\
\hline 1 & $57 / \mathrm{M}$ & Cerebral aneurysm & 7 & Sputum, T/A & Pneumonia & Imipenem & Improved \\
\hline 2 & $20 / \mathrm{M}$ & Multiple trauma & 12 & T/A, wound, i.v. line & Bacteraemia? & $\begin{array}{l}\text { Imipenem }+ \\
\text { tobramycin }\end{array}$ & Died \\
\hline 3 & $40 / F$ & $\begin{array}{l}\text { Multiple trauma, diabetes } \\
\text { mellitus }\end{array}$ & 2 & $\begin{array}{l}\text { i.v. line, wound, } \\
\text { skin, vagina, blood }\end{array}$ & Bacteraemia & Imipenem & Improved \\
\hline 4 & $54 / F$ & $\begin{array}{l}\text { Epilepsy, asthma, } \\
\text { aspiration pneumonia }\end{array}$ & 5 & Urine, sputum, T/A & Pneumonia & Imipenem & Improved \\
\hline 5 & $74 / F$ & Ruptured aortic aneurysm & 10 & Blood & Bacteraemia & Imipenem & Improved \\
\hline 6 & $80 / \mathrm{M}$ & $\begin{array}{l}\text { Multiple trauma, } \\
\text { respiratory arrest }\end{array}$ & 20 & $\mathrm{~T} / \mathrm{A}$ & Pneumonia & Imipenem & Died \\
\hline 7 & $59 / \mathrm{M}$ & Multiple trauma & 14 & $\begin{array}{l}\text { T/A, wound, i.v. } \\
\text { line, skin }\end{array}$ & Pneumonia & Imipenem & Improved \\
\hline 8 & $74 / \mathrm{M}$ & $\begin{array}{l}\text { Chronic obstructive lung } \\
\text { disease, pneumonia }\end{array}$ & 19 & Sputum, T/A & Pneumonia & $\begin{array}{l}\text { Imipenem }+ \\
\text { amikacin }\end{array}$ & Improved \\
\hline 9 & $58 / \mathrm{F}$ & $\begin{array}{l}\text { CLL, acoustic neuroma, } \\
\text { V-P shunt, respiratory } \\
\text { failure }\end{array}$ & 19 & $\mathrm{~T} / \mathrm{A}$, sputum & Pneumonia & $\begin{array}{l}\text { Imipenem }+ \\
\text { amikacin }\end{array}$ & Improved \\
\hline 10 & $25 / \mathrm{M}$ & Multiple trauma & 20 & $\mathrm{~T} / \mathrm{A}$, wound & Pneumonia & None & Died \\
\hline 11 & $68 / \mathrm{M}$ & Ruptured aortic aneurysm & 14 & Sputum, T/A, i.v. line & Pneumonia & $\begin{array}{l}\text { Imipenem }+ \\
\text { tobramycin }\end{array}$ & Died \\
\hline
\end{tabular}

APACHE II, acute physiology and chronic health evaluation; T/A, tracheal aspirate; i.v., intravascular; CLL, chronic lymphatic leukaemia; $\mathrm{V}-\mathrm{P}$, ventriculo-peritoneal.

presence of multi-resistant Acinetobacter spp. on 27 April 1993, and subsequently, was negative. Occasional antibiotic-susceptible environmental isolates of $A$. lwoffi $i$ (as identified by the API 20NE system) were made throughout the entire period, but these did not appear to be in any way related to the multi-resistant Acinetobacter isolates involved in patient infections.

Measures taken to control the spread of the multiresistant Acinetobacter spp. included transfer to the single cubicle in the unit (when available or possible according to the patient's condition), cohort nursing, the use of plastic disposable aprons and gloves when caring for positive patients, and encouraging staff to hand-wash with alcoholic chlorhexidine (Hibiscrub; Zeneca) $0.5 \% \mathrm{v} / \mathrm{v}$ before and after patient contact. These measures were continued when the patient was discharged from the unit to a general ward. All staff were also instructed to use an alcohol hand rub (Hydrex; De Puy Healthcare, Leeds) when not in direct contact with the patient but when consulting patients' case notes, drug charts, records, etc. Finally, the ITU was emptied and underwent a major clean with Hospec detergent (Darlylever, Bolton) during Oct. 1992, and with Hospec detergent and a generic phenolic disinfectant (De Puy Healthcare) in April 1993.

\section{Characteristics of multi-resistant Acinetobacter strains isolated during the outbreak}

The outbreak was recognised initially on the basis of the resistance profile of the isolates recovered. All patient and environmental multi-resistant Acineto- bacter isolates obtained in the present outbreak had identical antibiograms and API 20NE identification profiles, and no infections caused by a "non-outbreak" strain of Acinetobacter were identified during this period. Table III lists the characteristics of a random representative selection of eight patient and environmental multi-resistant Acinetobacter isolates from the outbreak in comparison with two unrelated "non-outbreak" Acinetobacter strains isolated a decade previously in 1982. The eight isolates (nos. 1-8) from the present outbreak were identified by the API $20 \mathrm{NE}$ system as $A$. baumannii (table III), although interpretation of some of the reactions in the test strips that determined the biotype (but did not influence the species identification) was subjective and inoculum dependent. The two non-outbreak isolates from 1982 had substantially different profiles and were identified by the API system as $A$. baumannii (isolate no. 9) and A. Iwoffii (isolate no. 10). The MICs (mg/L) of a range of antibiotics for the outbreak strains were identical within one doubling dilution (antibiotype R1: ampicillin, > 1024; cephradine, $>1024$; cefuroxime, 512; cefotaxime, 128; ceftazidime, 32; gentamicin, $>512$; tobramycin, 2; amikacin, 2; ciprofloxacin, 1; imipenem, 0.5 ; trimethoprim, 32; chloramphenicol, 512 ; tetracycline, $>512$; azlocillin, $>1024$ ). In contrast, the two non-outbreak isolates from 1982 showed significant variations. Isolate no. 9 (antibiotype R2) was significantly more sensitive to $\beta$-lactams and gentamicin (corresponding MICs of $64,512,64,32$, $16,16,<1,2,1,0.5,16,512,256$ and $<8 \mathrm{mg} / \mathrm{L}$, respectively), whereas isolate no. 10 (antibiotype R3) was essentially sensitive to all antibiotics tested with the exception of trimethoprim (MIC $512 \mathrm{mg} / \mathrm{L}$ ). 
Table III. Comparison of the characteristics of a random representative selection of eight Acinetobacter isolates obtained during the 1992-93 outbreak with two "nonoutbreak" strains from 1982

\begin{tabular}{|c|c|c|c|c|c|}
\hline $\begin{array}{l}\text { Isolate } \\
\text { no. }\end{array}$ & $\begin{array}{l}\text { Infected } \\
\text { patient no.* } \\
\text { or site } \\
\text { (date) }\end{array}$ & $\begin{array}{c}\text { API 20NE } \\
\text { biotype }\end{array}$ & Antibiotype $\dagger$ & $\begin{array}{l}\text { PFGE } \\
\text { type }\end{array}$ & Ribotype $\dagger$ \\
\hline 1 & $\begin{array}{l}\text { Patient } 4 \\
(11 / 92)\end{array}$ & 0000073 & R1 & $\mathrm{P} 1$ & $\mathrm{Al}$ \\
\hline 2 & $\begin{array}{l}\text { Patient } 3 \\
(11 / 92)\end{array}$ & 0000073 & $\mathrm{R} 1$ & P1 & $\mathrm{A} 1$ \\
\hline 3 & $\begin{array}{l}\text { Patient } 6 \\
(12 / 92)\end{array}$ & 0000073 & $\mathrm{R} 1$ & P2 & Al \\
\hline 4 & $\begin{array}{l}\text { Patient } 7 \\
(1 / 93)\end{array}$ & 0000073 & $\mathrm{R} 1$ & P1 & $\mathrm{Al}$ \\
\hline 5 & $\begin{array}{c}\text { Colonised } \\
\text { patient }(2 / 93)\end{array}$ & 0000073 & $\mathrm{R} 1$ & P1 & $\mathrm{Al}$ \\
\hline 6 & $\begin{array}{l}\text { Patient } 11 \\
(2 / 93)\end{array}$ & 0000073 & $\mathrm{R} 1$ & P1 & $\mathrm{A} 1$ \\
\hline 7 & $\begin{array}{c}\text { Tubing } f \\
(2 / 93)\end{array}$ & 0000073 & R1 & P1 & A1 \\
\hline 8 & $\begin{array}{c}\text { Bed wheels§ } \\
(2 / 93)\end{array}$ & 0000073 & $\mathrm{R} 1$ & P1 & A1 \\
\hline 9 & $\begin{array}{c}\text { Wound swab } \\
(1 / 82)\end{array}$ & 0041073 & $\mathrm{R} 2$ & P3 & $\mathrm{A} 2$ \\
\hline 10 & $\begin{array}{l}\text { Urine } \\
(6 / 82)\end{array}$ & 0000010 & R3 & P4 & A3 \\
\hline
\end{tabular}

\section{*See table II.}

†See text.

$¥$ †rom environment of the colonised patient (isolate 5).

$\S$ From environment of the infected patient (isolate 3 ).

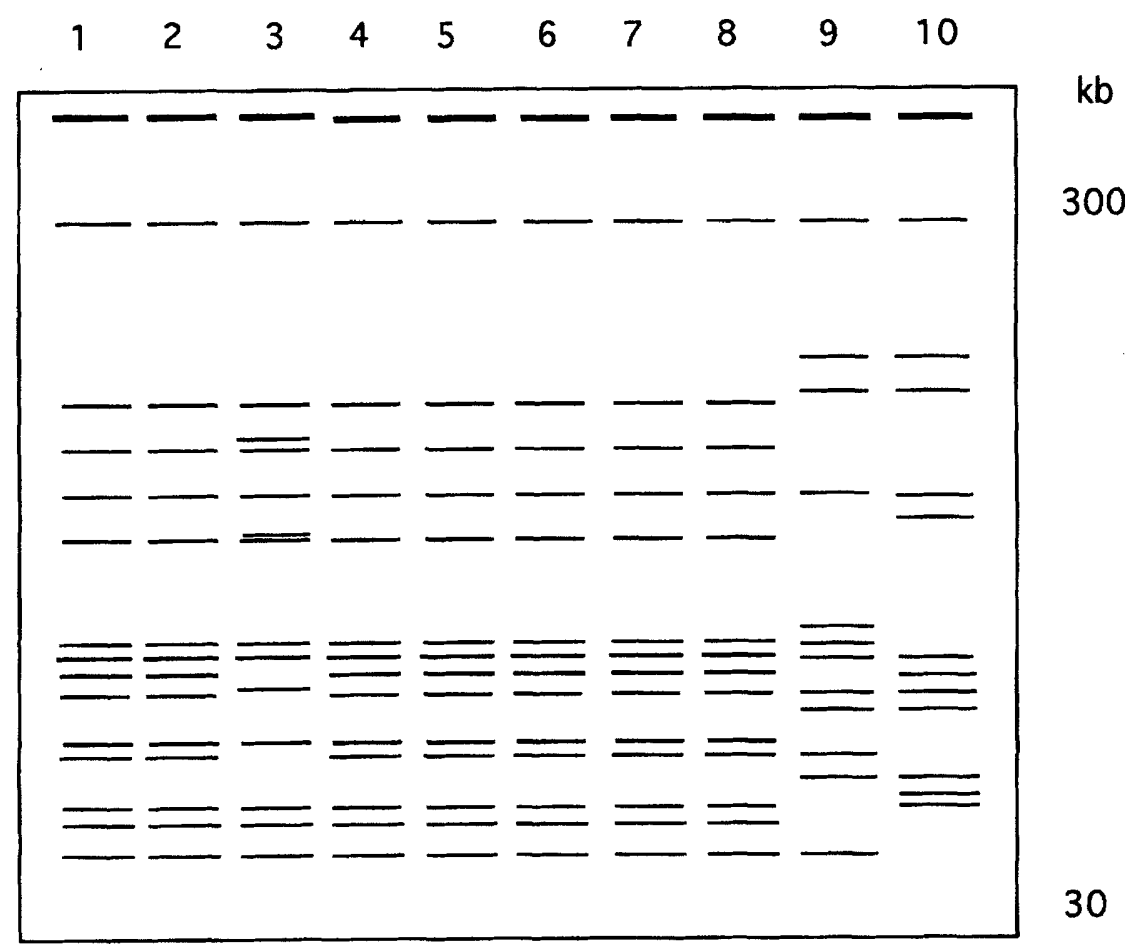

Fig. 1. Computer-generated analysis of the ApaI PFGE fingerprints obtained for outbreak and non-outbreak strains of Acinetobacter. Track numbers correspond to the isolate numbers listed in table III.

Fig. 1 shows a computer-generated analysis of the ApaI chromosomal fingerprints generated for the 10 representative isolates after PFGE. Single-band differences between strains are not normally considered significant in PFGE, and on this basis only one outbreak isolate (no. 3) showed any significant vari- ation, possibly as a result of incomplete DNA digestion. The close relationship between the outbreak isolates was confirmed by probing chromosomal fingerprints with a DIG-labelled oligonucleotide probe specific for repetitive rRNA genes (fig. 2). The discriminative power of these methods was 




Fig. 2. Computer-generated analysis of a Southern blot of the Apal fingerprints shown in fig. 1 probed with a DIG-labelled oligonucleotide probe specific for repetitive $16 \mathrm{~S}$ rRNA genes. Track numbers correspond to the isolate numbers listed in table III.

demonstrated by the significantly different fingerprints obtained with the two non-outbreak isolates from 1982. Other multi-resistant $A$. baumannii isolates obtained from geographically distinct locations in the UK and Europe also gave significantly different PFGE fingerprints (results not shown).

\section{Discussion}

The clinical findings from this outbreak are similar to previous reports in which a predominance of ITU patients has also been noted. ${ }^{2.4 .26-28}$ The majority of colonised or infected patients in this study were seriously ill. as indicated by their APACHE II score, and all had been ventilated artificially throughout most of their ITU stay. Many patients first acquired an Acinetobacter sp. during the week after admission, a finding similar to that described in a 2-year outbreak in Denmark involving over 100 patients. ${ }^{28}$ This suggests an ITU source, with transmission occurring probably via patient to staff followed by staff to patient contact.

It is not always apparent whether the isolation of Acinetobacter spp. represents colonisation or infection. as many patients in ITU are difficult to assess clinically and. furthermore, the presence of fever may be a result of causes other than infection, such as multiple trauma. Colonisation of more than one site, including isolation from an intravascular line, is not followed necessarily by infection requiring antimicrobial chemotherapy. There was a wide variety of underlying disease in a report of 27 patients with acinetobacter bacteraemia, ${ }^{26}$ but this previous outbreak was not confined to an ITU as patients were located on medical, surgical, paediatric and neuro- surgical wards. In the present study, four $(36 \%)$ of the 11 infected patients died either directly or indirectly from acinetobacter infection, a proportion similar to that reported by Seifert and Baginski, ${ }^{27}$ but higher than that found in the study by Smegmo ${ }^{26}$ in which only three of 18 patients died. In contrast, only one, or at most two, of 111 patients developed systemic infection in a Danish outbreak. ${ }^{28}$ This considerable variation in outcome may be explained by a combination of variations in underlying disease, differences in criteria used to diagnose infection, the type of patient population studied, and the virulence of the local strain of Acinetobacter implicated in each outbreak.

The course of the present outbreak was characterised by the isolation of essentially indistinguishable isolates of Acinetobacter from patients and environmental sources on an intermittent but overlapping basis. This probably indicates substantial contamination of the immediate environment by heavily colonised or infected patients, either directly or indirectly via the hands or clothing of staff. The epidemiology of acinetobacter infection has been reviewed previously, ${ }^{2,3}$ and the impressive list of environmental sites from where this bacterium has been isolated includes humidifiers, hand-wash basins and mattresses. Spread to bedside cupboards and sinks was detected in 12 of 104 samples taken during an outbreak occurring in a community hospital, ${ }^{29}$ whilst patient chart covers and the hands of staff were also positive in a paediatric ITU. ${ }^{28}$ The hands of staff caring for infected patients were not sampled in the present study, but had this been done it is possible that the findings of other studies-in which staff hand carriage ranged from $8 \%$ to $24 \%$-would have been 
reproduced. ${ }^{28.30}$ Patient chart contamination has also been described. ${ }^{30}$ and the use of an alcohol hand-rub after contact was therefore, recommended, although, regrettably, it was not possible to investigate this possible reservoir of contamination on a scientific basis. Respiratory tubing. nebulisers and ventilators have also been implicated as sources of infection...31 Acinetobacter spp. were not isolated from respiratory tubing in the present study and, although ventilators were not sampled, there was no correlation between infected or colonised patients and the ventilator type when compared with non-infected or non-colonised patients.

The outbreak described in this paper lasted approximately 6 months and occurred during the winter and spring period when many patients with chronic lung disease require admission to the ITU for artificial ventilation. Transfer of infected or colonised patients to the single isolation cubicle, cohort nursing. emphasis on the importance of handwashing, and the use of disposable aprons and gowns during patient contact. appear to have been effective in helping to curtail the outbreak. It is not certain whether these measures alone or the closure of the unit for decontamination were more important. but the seasonal nature of previous outbreaks in Nottingham may also be significant. The seasonal occurrence of outbreaks of acinetobacter infection has also been described elsewhere, ${ }^{29.32}$ but a higher incidence during the late autumn. winter and spring may simply reflect the prevalence of respiratory tract infection at this time of year.

\section{References}

1. Grimont PAD. Bouvet PJM. Taxonomy of Acinetobacter. In Towner KJ. Bergogne-Bérézin E. Fewson CA (eds) The biology of Acinetobacter. Taxonomy. clinical importance. molecular biology. physiology. industrial relevance. New York, Plenum. 1991: 25-36.

2. Bergogne-Bérézin E. Joly-Guillou ML. Vieu JF. Epidemiology of nosocomial infections due to Acinetobacter calcoaceticus. J Hosp Infect 1987: 10 : 105-113.

3. Noble WC. Hospital epidemiology of Acinetobacter infection. In: Towner KJ. Bergogne-Bérézin E. Fewson CA (eds) The biology of Acinetobacter. Taxonomy. clinical importance. molecular biology. physiology. industrial relevance. New York. Plenum. 1991: 53-62.

4. Joly-Guillou ML. Bergogne-Bérézin E. Vieu JF. Epidemiology of Acincrobacter and its resistance to antibiotics in hospitats a 5-year evaluation. Presse Med 1990: 19: 357361

5. Peacock JE. Sorrell L. Sottile FD. Price LE. Rutala WA Nosocomial respiratory tract colonization and infection with aminoglycoside-resistant Acinetobacter calcoaceticus var anitratus: epidemiologic characteristics and clinical significance. Infect Control Hosp Epidemiol 1988: 9 $302-308$

6. Hartsein Al. Morthland VH. Rourke JW et al. Plasmid DNA fingerprinting of Acinetobacter calcoaceticus subspecies anitratus from intubated and mechanically ventilated patients. Infe't Control Epidemiol 1990: 11: 531-538.

7. Beck-Sagué CM. Jarvis WR. Brook JH et al. Epidemic bacteriemia due to Acine tobacter batmannii in five intensive care units. Am J Epidemiol 1990: 132: 723-733.

8. Bergogne-Bérézin E, Joly-Guillou ML. Antibiotic resistance mechanisms in Acinetohacter. In: Towner KJ. BergogneBérézin E. Fewson CA (eds) The biology of Acinetobatter Taxonomy, clinical importance. molecular biology, physi-
The measures used to control and ultimately end the outbreak, especially the emphasis on handwashing before and after patient contact and when handling case notes, were accompanied by a failure to detect the epidemic Acinetobacter strain in subsequent environmental specimens. However, it is possible that small numbers of this multi-resistant epidemic strain remain in the environment, from where they can cause further outbreaks of infection when conditions are appropriate. Consequently, we believe that continued surveillance of ITU patients and occasional environmental sampling, combined with identification and typing of Acinetobacter isolates, is important in anticipating future problems. At present, no single typing method has been evaluated properly for all Acinetobacter spp. A number of newer molecular typing methods based on nucleic acid analysis show considerable promise, but require further validation, particularly with Acinetobacter strains from nonclinical sources. The combination of typing methods used in the present study was effective in demonstrating the close relationship between outbreakassociated strains and in discriminating these strains from unrelated environmental isolates. The continued development and evaluation of reliable methods for typing Acinetobacter isolates from patients and the environment is a key element in enhancing our understanding of the epidemiology of this increasingly important nosocomial pathogen and in preventing or controlling subsequent outbreaks.

We are indebted to Trent Regional Health Authority for their support of this work.

ology. industrial relevance. New York, Plenum. 1991: 83-115.

9. Allen KD. Green HT. Hospital outbreak of multi-resistant Acinetobacter anitratus: an airborne mode of spread? $J$ Hosp Infect 1987; 9: 110-119.

10. Bouvet PJM. Typing of Acinetobacter. In: Towner KJ, Bergogne-Bérézin E. Fewson CA (eds) The biology of Acinetobacter. Taxonomy, clinical importance, molecular biology, physiology, industrial relevance. New York, Plenum. 1991: 37-51.

11. Dijkshoorn L. Van Vianen W, Degener JE, Michel MF. Typing of Acinetobacter calcoaceticus strains isolated from hospital patients by cell envelope protein profiles. Epidemiol Infect 1987: 99: 659-667.

12. Dijkshoorn L. Wubbels JL, Beunders AJ. Degener JE, Boks AL. Michel MF. Use of protein profiles to identify Acinetobacter calcoaceticus in a respiratory care unit. $J$ Clin Pathol 1989: 42: 853-857.

13. Gouby A. Carles-nurit M-J, Bouziges N. Bourg G. Mesnard R, Bouvet PJM. Use of pulsed-field gel electrophoresis for investigation of hospital outbreaks of Acinetobacter baumannii. J Clin Microbiol 1992: 30: 1588-1591.

14. Gerner-Smidt P. Ribotyping of the Acinetohacter calcoaceticusAcinetobacter baumannii complex. J Clin Microbiol 1992. 30 : 2680-2685.

15. Gräser Y. Klare I. Halle E et al. Epidemiological study of an Acimetobacter baumannii outbreak by using polymerase chain reaction fingerprinting. $J$ Clin Microbiol 1993; 31 2417-2420.

16. Knaus WA. Draper EA. Wagner DP. Zimmerman JE. APACHE II: a severity of disease classification system. Crit Care Med 1985: 13: 818-829.

17. Garner JS, Jarvis WR. Emori TC. Horan TC. Hughes JM. CDC definitions for nosocomial infections - 1988. Am J Infect Control 1988; 16: 128-140.

18. A preliminary report of the Steering Group of the Second 
National Prevalence Survey. National prevalence survey of hospital acquired infections: definitions. $J$ Hosp Infect 1993; $24: 69-76$.

19. Hawkey PM, Lewis DA (eds). Medical bacteriology. A practical approach. Oxford, IRL Press. 1989.

20. Ispahani P, Pearson NJ, Greenwood D. An analysis of community and hospital-acquired bacteraemia in a large teaching hospital in the United Kingdom. $Q J$ Med 1987; 63: $427-440$.

21. Faling LJ. New advances in diagnosing nosocomial pneumonia in intubated patients. Part I. Am Rev Respir Dis 1988; 137: 253-255.

22. Lach V. Performance of the surface air system air samplers. $J$ Hosp Infect 1985; 6: 102-107.

23. Barrow GI, Feltham RKA (eds). Cowan and Steel's Manual for the identification of medical bacteria, 3rd edn. Cambridge, Cambridge University Press. 1993.

24. Curran R, Hardie KR, Towner KJ. Analysis by pulsed-field gel electrophoresis of insertion mutations in the transferrinbinding system of Haemophilus influenzae type b. $J \mathrm{Med}$ Microbiol 1994; 41: 120-126.

25. Amann RI, Binder BJ, Olson RJ, Chisholm SW, Devereux R, Stahl DA. Combination of $16 \mathrm{~S}$ rRNA-targeted oligonucleotide probes with flow cytometry for analyzing mixed microbial populations. Appl Environ Microbiol 1990; 56: 1919-1925.

26. Smegmo RA. Endemic nosocomial Acinetobacter calcoaceticus bacteremia. Clinical significance, treatment and prognosis. Arch Int Med 1985; 145: 2174-2179.

27. Seifert H, Baginski R. The clinical significance of Acinetobacter baumannii in blood cultures. Int J Med Microbiol Virol Parasitol Infect Dis 1992; 277: 210-218.

28. Gerner-Smidt P. Endemic occurrence of Acinetobacter calcoaceticus biovar anitratus in an intensive care unit. $J$ Hosp Infect 1987; 10: 265-272.

29. Crombach WHJ, Dijkshoorn L, van Noort-Klaassen M, Niessen J, van Knippenberg-Gordebeke G. Control of an epidemic spread of a multi-resistant strain of Acinetobacter calcoaceticus in a hospital. Intensive Care Med 1989; 15: 166-170.

30. Getchell-White SI, Donowitz LG, Gröschel DHM. The inanimate environment of an intensive care unit as a potential source of nosocomial bacteria: evidence for long survival of Acinetobacter calcoaceticus. Infect Control Hosp Epidemiol 1989; 10: 402-407.

31. Hartstein AI, Rashad AL, Liebler JM et al. Multiple intensive care unit outbreak of Acinetobacter calcoaceticus subspecies anitratus respiratory infection and colonization associated with contaminated, reusable ventilatory circuits and resuscitation bags. Am J Med 1988; 85: 624-631.

32. Buisson $Y$, Tran Van Nhieu G, Ginot L et al. Nosocomial outbreaks due to amikacin-resistant tobramycin-sensitive Acinetobacter species: correlation with amikacin usage. $J$ Hosp Infect 1990; 15: 83-93. 